\title{
Glycine blocks opening of a death channel in cultured hepatic sinusoidal endothelial cells during chemical hypoxia
}

\author{
Y Nishimura ${ }^{1}$ and JJ Lemasters ${ }^{*, 1}$ \\ ${ }^{1}$ Department of Cell Biology \& Anatomy, School of Medicine, University of North \\ Carolina at Chapel Hill, Chapel Hill, NC 27599-7090, USA \\ * Corresponding author: Dr JJ Lemasters, Department of Cell Biology \& \\ Anatomy, University of North Carolina at Chapel Hill, Campus Box 7090, 236 \\ Taylor Hall, Chapel Hill, NC 27599-7090, USA Tel: (919) 966-5507 FAX: (919) \\ 966-1856; E-mail: lemaster@med.unc.edu
}

Received 27.4.00; revised 3.1.01; accepted 2.3.01

Edited by $D$ Green

\begin{abstract}
Using confocal microscopy, we investigated mechanisms underlying loss of plasma membrane integrity during necrotic death of cultured hepatic sinusoidal endothelial cells exposed to $2.5 \mathrm{mM}$ potassium cyanide (chemical hypoxia). After 2-3 h, the anionic fluorophore calcein abruptly began to enter the cytosol, and nuclei labeled with cationic propidium after another 2-5 min. As calcein permeated, growth of blebs on the plasma membrane accelerated. Lucifer yellow, another anionic fluorophore, entered identically to calcein, whereas high molecular weight dextrans $(40-2000 \mathrm{kDa})$ entered like propidium. Glycine slowed, but did not prevent calcein entry, whereas permeation of propidium and high molecular weight dextrans was blocked completely by glycine. These findings suggest that opening of a glycine-sensitive organic anion channel, or death channel, precipitates a metastable state characterized by rapid cell swelling and bleb growth. This metastable state culminates in non-specific breakdown of the plasma membrane permeability barrier and irreversible cell death. Cell Death and Differentiation (2001) 8, 850-858.
\end{abstract}

Keywords: blebs; calcein; cell death; chemical hypoxia; death channel; glycine; plasma membrane; propidium iodide

Abbreviations: KRH, Krebs-Ringer-HEPES buffer; MDCK, MadinDarby canine kidney cells; N.A., numerical aperture

\section{Introduction}

Disturbances of plasma membrane structure and function are major features of necrotic cell death from hypoxia and reoxygenation. Membrane changes include surface bleb formation, changes of lipid fluidity and lateral distribution, and alterations of phospholipid composition. ${ }^{1-7}$ An abrupt breakdown of the plasma membrane permeability barrier is characteristic of the final stage of necrotic cell death. ${ }^{1,2},{ }^{7-9}$ In hepatocytes, a short metastable state precedes breakdown of the plasma membrane permeability barrier. During this metastable state, blebs increase rapidly in size, trapped anionic fluorophores leak from the cytosol, onset of the mitochondrial permeability transition occurs, and lysosomes disintegrate. ${ }^{1,6,7,10}$ This metastable state culminates with physical rupture of a bleb and consequent equilibration of intracellular and extracellular contents. ${ }^{7,10}$

Glycine strongly protects many cell types against lethal cell injury due to a variety of stresses. ${ }^{11-21}$ Protection by glycine occurs at a late phase of cell injury, since addition of glycine long after induction of cell injury can prevent loss of cell viability. ${ }^{16-21}$ Recently, glycine was reported to block opening of aqueous pores with an apparent diameter of 5$6 \mathrm{~nm}$ in the plasma membrane of dying Madin-Darby canine kidney (MDCK) cells. ${ }^{22}$

In hepatocytes and hepatic sinusoidal endothelial cells, glycine prevents lethal ischemia/reperfusion injury when administered only during reperfusion. ${ }^{16,17,21}$ However, subsequent removal of glycine promptly precipitates cell death. ${ }^{16,17}$ Since glycine cytoprotection acts at a late stage of injury, the aim of the present work was to determine how glycine influences development of the metastable state and changes of plasma membrane permeability that occur just prior to cell death. Glycine-sensitive death of hepatic sinusoidal endothelial cells is a key factor in storage/ reperfusion injury to livers stored for transplantation. ${ }^{15,16,23}$ Accordingly, we used primary cultures of these cells for the present study. Our results indicate that glycine inhibits an organic anion channel that opens just prior to cell death. We propose that opening of this 'death channel' initiates the metastable state.

\section{Results \\ Plasma membrane permeability during chemical hypoxia}

To characterize changes of plasma membrane permeability during ATP depletion, cultured sinusoidal endothelial cells were exposed to $2.5 \mathrm{mM} \mathrm{KCN}$ in a buffer containing the extracellular fluorescent markers, $30 \mu \mathrm{M}$ calcein and $3 \mu \mathrm{M}$ propidium iodide. The calcein anion is a membraneimpermeant fluorophore of molecular weight equal to $623 \mathrm{Da}$. The propidium cation is a $414 \mathrm{Da}$ fluorophore that is also impermeable to the lipid bilayer. Previous studies in cultured hepatocytes showed that both fluorophores penetrate the plasma membrane as onset of cell death occurs. ${ }^{10}$ Propidium (added as its iodide salt) stains non-viable nuclei exactly as trypan blue by intercalating into double-stranded nucleic acids with enhancement of its red fluorescence. ${ }^{24}$ In confocal microscopy, calcein outlines individual cells with its bright green fluorescence. Accordingly, cells are dark voids in 
the green calcein fluorescence, which fill at the onset of cell death. $^{10}$

Like hepatocytes, cultured sinusoidal endothelial cells excluded both calcein and propidium during aerobic incubation (Figure 1, Baseline). When cells were subsequently incubated with $\mathrm{KCN}$, nuclear labeling with propidium occurred after 135 to $180 \mathrm{~min}$ (Figure 1, upper panels, white arrows). At nearly the same time, calcein penetrated the cells, and the dark negative images of the cells filled with green fluorescence (Figure 1, lower panels, black arrows). Penetration of calcein and propidium indicated loss of plasma membrane integrity.

Close examination of the temporal sequence of labeling indicated that calcein permeation occurred in advance of propidium nuclear labeling. For example in Figure 1, calcein fully penetrated the cell after 165 min (Figure 1, 165', lower panel, double arrow), prior to any detectable permeation of propidium. However, at the next time point measured, propidium strongly labeled the nucleus of the same cell (Figure 1, 180', upper panel, double arrow).

Loss of plasma membrane integrity at cell death causes release of enzymes and other high molecular weight solutes from the cytosol. Accordingly, we investigated the permeation of a high molecular weight fluorescein-dextran (40 kDa) through the plasma membrane as cell death occurred. As shown in Figure 2, viable cells excluded both propidium and fluorescein-dextran of $40 \mathrm{kDa}$ after $120 \mathrm{~min}$ of chemical hypoxia (Figure 2, 120'). After $180 \mathrm{~min}$, labeling with propidium and penetration of fluorescein-dextran occurred simultaneously, as indicated by arrows. Propidium labeling and fluorescein-dextran penetration occurred closely together. For example, after 180 min of chemical hypoxia, the
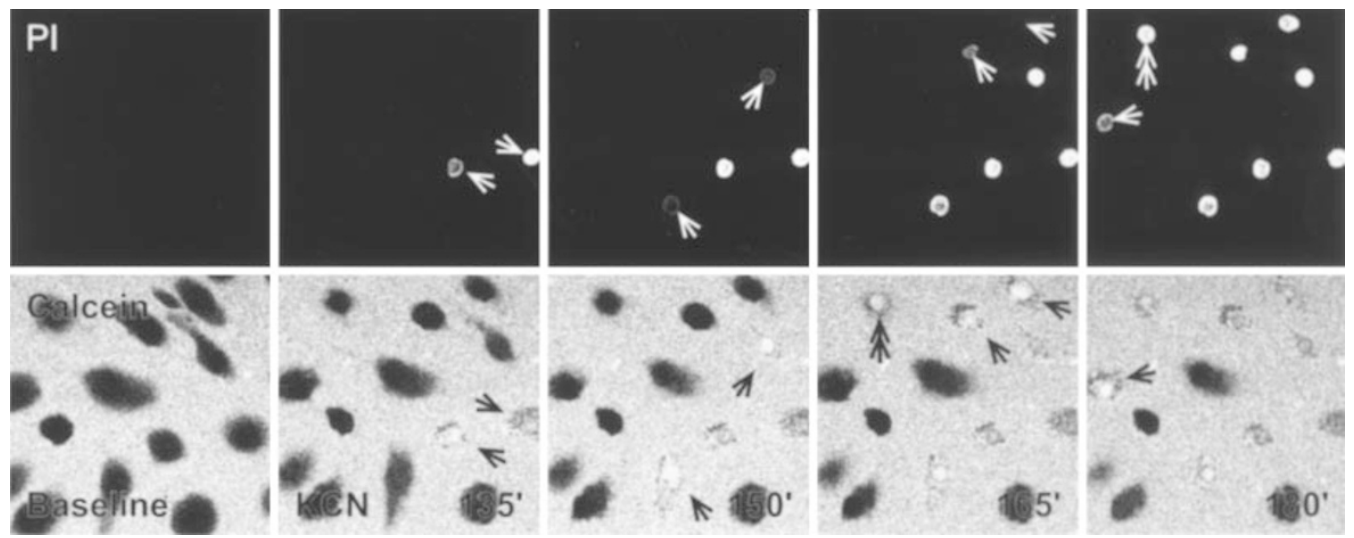

Figure 1 Permeation of the plasma membrane by calcein and propidium during chemical hypoxia. One-day cultured sinusoidal endothelial cells were incubated with $30 \mu \mathrm{M}$ calcein and $3 \mu \mathrm{M}$ propidium iodide. The green fluorescence of calcein and red fluorescence of propidium were imaged by confocal microscopy. During aerobic incubation, individual cells excluded both propidium and calcein. Thus, no nuclear staining with propidium was evident (Baseline, upper panel), and the green fluorescence of extracellular calcein outlined the individual cells as dark oblong voids (Baseline, lower panel). After incubation with $2.5 \mathrm{mM}$ KCN (chemical hypoxia), two nuclei labeled with propidium after $135 \mathrm{~min}\left(135^{\prime}\right.$, white arrows). Additional nuclei labeled at later time points (150' - 180', white arrows) When cells labeled with propidium, calcein penetrated the cells to fill the dark cellular voids with green fluorescence $\left(135^{\prime}-180^{\prime}\right.$, black arrows). During the progression of injury, cells were observed that took up calcein but were not yet labeled with propidium (165', double black arrow). Such cells labeled with propidium at a subsequent time point (180', double white arrow). One experiment representative of four
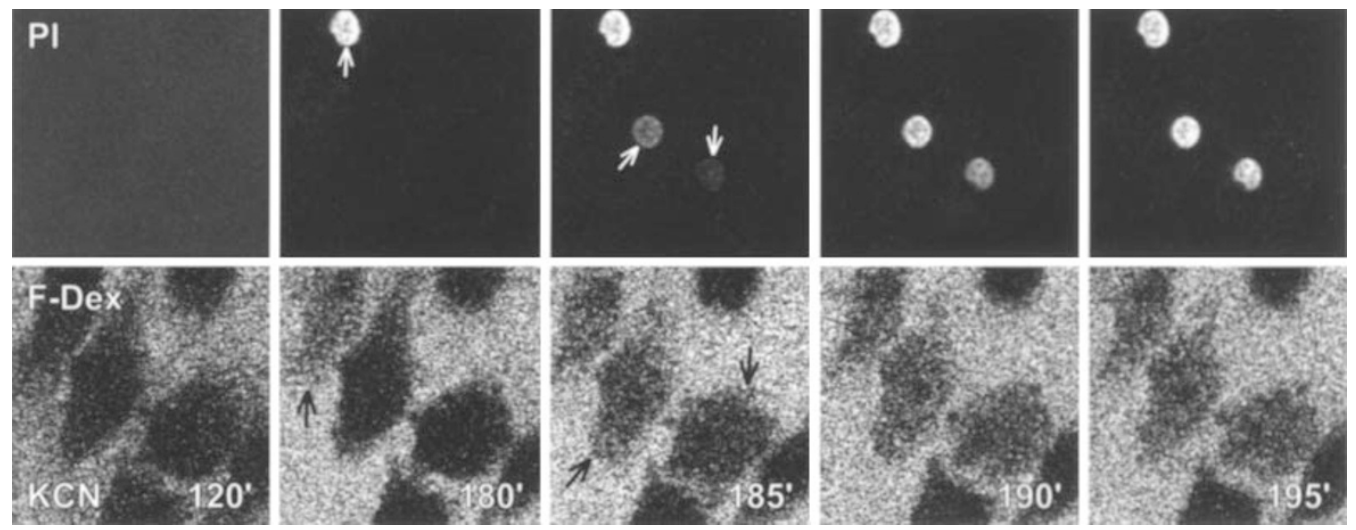

Figure 2 Permeation of propidium and fluorescein-dextran during chemical hypoxia. Cells were incubated with $3 \mu \mathrm{M}$ propidium iodide, and $2.5 \mathrm{mM} \mathrm{KCN}$ was added. Fluorescein-dextran $(40 \mathrm{kDa}, 0.3 \mathrm{mg} / \mathrm{ml})$ was added after $120 \mathrm{~min}$, and confocal images of green (fluorescein-dextran) and red (propidium) fluorescence were collected. Viable cells excluded both propidium (120', upper panel) and fluorescein-dextran (120', lower panel). After 180 min and 185 min, cells became newly labeled with propidium (180' and 185', white arrows). At the same time, fluorescein-dextran filled the cell interior (180' and 185', black arrows). Propidium labeling and fluorescein-dextran permeation were complete after 190-195 min. One experiment representative of four 
two cells in the center of the field had not taken up either propidium or fluorescein-dextran. After $185 \mathrm{~min}$, however, both propidium (white arrows) and fluorescein-dextran (black arrows) had partially entered the cells. After $190 \mathrm{~min}$, penetration of both propidium and fluoresceindextran was maximal. Unlike calcein, fluorescein-dextran never labeled cells to the same intensity as the extracellular medium. Presumably, intracellular components were limiting the volume available to the high molecular weight fluorophore. Cells whose nuclei had not yet labeled with propidium continued to exclude fluorescein-dextran (Figure $\left.2,190^{\prime}-195^{\prime}\right)$. Similar results occurred with dextrans up to $500 \mathrm{kDa}$ (data not shown). Taken together, the results of Figures 1 and 2 indicated that nuclear labeling with cationic propidium and permeation of the plasma membrane to large molecular weight solutes occurred at the same time, whereas permeation to anionic calcein occurred sooner.

We next characterized changes of plasma membrane permeability in relation to formation of surface blebs. Cells were subjected to chemical hypoxia in the presence of $30 \mu \mathrm{M}$ calcein and $3 \mu \mathrm{M}$ propidium iodide in the extracellular buffer. Brightfield and fluorescence images were collected simultaneously. In the experiment shown in Figure 3 , permeation of calcein began after about $3 \mathrm{~h}$ of chemical hypoxia (Figure 3A, 180', middle panel, arrow). Subsequently, over the next few minutes, calcein fluorescence filled the cell interior, but propidium staining of the nucleus did not yet occur (Figure 3A, 184', middle and upper panels). As calcein penetrated the cell, but before propidium labeling had begun, plasma membrane blebs formed and increased progressively in size (Figure 3A, 183 and $184^{\prime}$, dotted arrowheads). Bleb growth continued even after calcein penetration was complete after about 5 min (Figure 3A. 189', lower panel). Since blebs grew upwards as well as outwards, bleb growth was sometimes best observed a few microns above the original plane of focus (Figure 3B). During the latter stage of bleb growth, propidium began to label the nucleus (Figure 3B, 186'$189^{\prime}$, arrows). As propidium labeling became maximal, all further bleb growth ceased (see Figure 6).

\section{Effect of glycine on permeability changes to the plasma membrane during chemical hypoxia}

These experiments were repeated in the presence of $3 \mathrm{mM}$ glycine, a concentration that prevents onset of sinusoidal endothelial cell death. ${ }^{17}$ In the presence of glycine, calcein permeation again occurred, beginning after 135-180 min of chemical hypoxia (Figure 4, black arrows). However, in contrast to our observations in the absence of glycine, the progress of calcein entry into the cells was much slower and 30-45 min were needed for maximum penetration instead of 2-5 min. (Figure 4, 180', lower panel). Thus, glycine slowed but did not prevent calcein permeation through the plasma membrane. Despite calcein permeation, no propidium labeling occurred in the presence of glycine (Figure 4 , $135^{\prime}-180^{\prime}$, upper panels). Subsequently, when glycinecontaining buffer was replaced with glycine-free buffer, virtually all cells labeled with propidium within 20 min (Figure 4, No Glycine, white arrows). Additionally, the few cells that had not previously labeled with calcein now took it up (Figure 4 , black arrows). Overall, these observations indicated that cationic propidium and anionic calcein entered cells by different pathways.

Calcein and propidium have similar molecular weights, but opposite charges. Thus, electrical charge may account for differences in how calcein and propidium penetrate dying cells. Accordingly, we examined the permeation during chemical hypoxia of $30 \mu \mathrm{M}$ lucifer yellow, another anionic fluorophore of similar molecular weight (443 Da) to calcein. In addition, to compare lucifer yellow permeation to that of a higher molecular weight solute, $0.3 \mathrm{mg} / \mathrm{ml}$ of rhodamine-dextran (40 kDa) was placed in the extracellular buffer. Prior to $\mathrm{KCN}$ addition, viable endothelial cells excluded both rhodamine-dextran and lucifer yellow (not shown). After 120 and $180 \mathrm{~min}$ of chemical hypoxia in the presence of glycine, rhodamine-dextran did not permeate the cells at all (Figure 5, upper panels), whereas lucifer yellow slowly permeated in the same fashion that calcein had (Figure 5, 120' and 180', lower panels, black arrows). Subsequently when glycine was removed, rhodaminedextran promptly crossed the plasma membrane to enter the cells (Figure 5, No Glycine, white arrows).

\section{Effect of glycine on bleb growth}

We also investigated the permeation of $2000 \mathrm{kDa}$ fluorescein-dextran. In the presence of glycine, neither $2000 \mathrm{kDa}$ fluorescein-dextran nor propidium penetrated cells after 180 min of chemical hypoxia (Figure 6). When glycine was removed, propidium again penetrated and labeled virtually all cell nuclei (Figure 6, white arrows). The $2000 \mathrm{kDa}$ dextran also penetrated, but intracellular fluorescence of the dextran was always less than extracellular fluorescence due to volume exclusion by cytoskeletal and membranous structures inside the cells. An advantage of the very high molecular weight dextran was that cellular contours could be imaged even after calcein permeation. Even in the presence of glycine, blebs formed during chemical hypoxia. The growth of blebs, however, was slow (Figure 6, 160'$180^{\prime}$, black arrows). After removal of glycine, bleb growth rapidly accelerated. In Figure 6, double arrows identify examples of rapid bleb growth after glycine removal. Once propidium labeling was complete, no further bleb growth occurred. Also during chemical hypoxia in the absence of glycine, $2000 \mathrm{kDa}$ fluorescein-dextran labeled cells in parallel to propidium uptake in the same fashion as lower molecular weight dextrans (not shown).

\section{Discussion}

\section{Metastable state preceding cell death}

Loss of integrity of the plasma membrane is the final event precipitating onset of necrotic cell death after ATP depletion. ${ }^{1,2,7}$ In hepatocytes, a metastable state develops just prior to rupture of the plasma membrane. This metastable state is characterized by rapid bleb growth, leakage of low molecular weight fluorophores from the cytosol, onset of the mitochondrial permeability transition, and disintegration of lyso- 


\section{A}
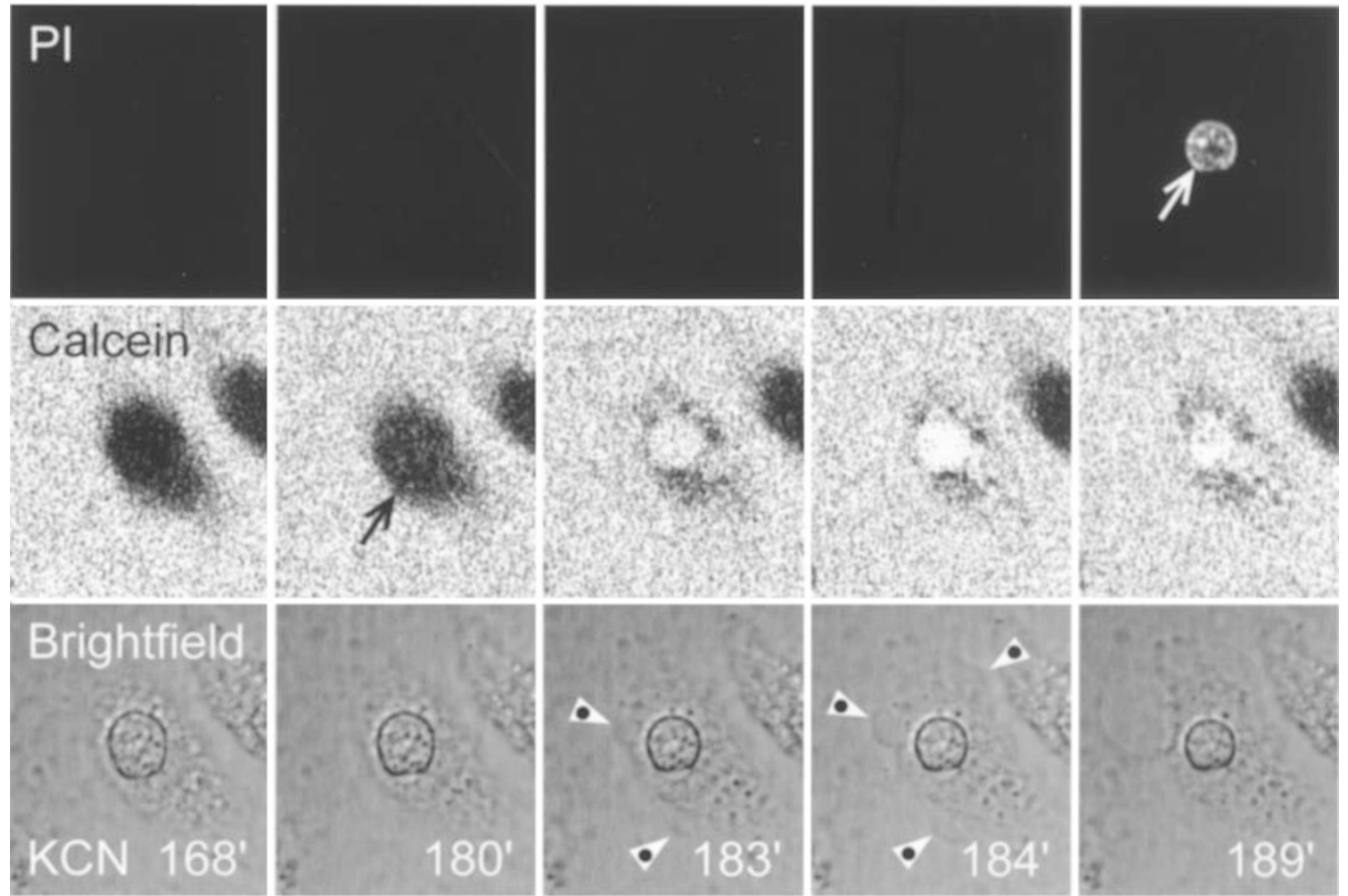

\section{B}
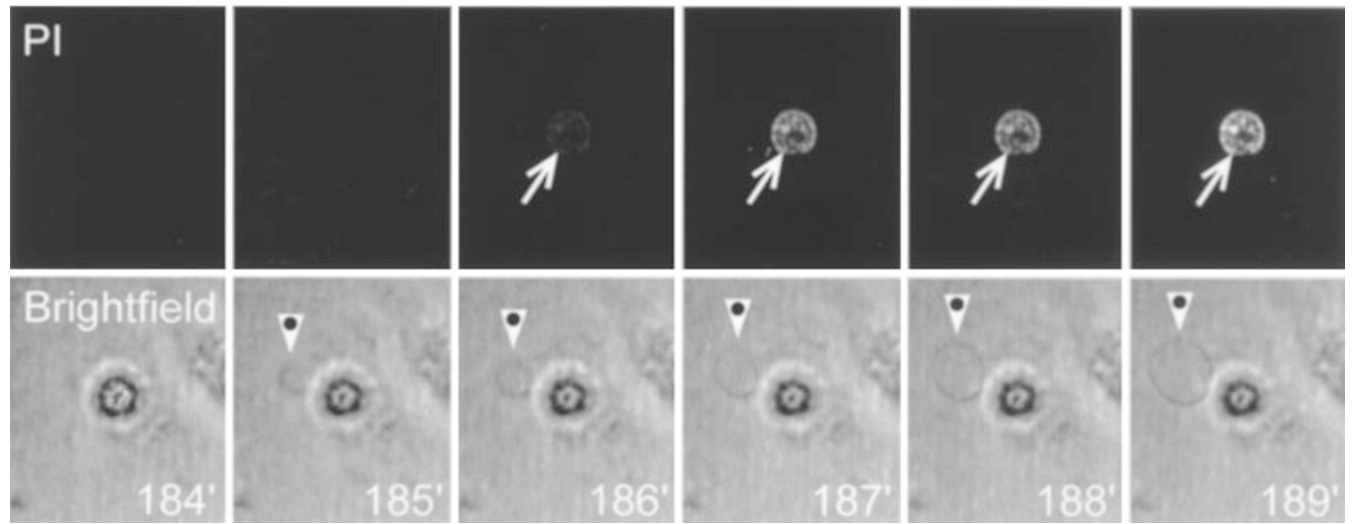

Figure 3 Kinetics of plasma membrane permeability changes and bleb formation during chemical hypoxia. Cells were incubated with $\mathrm{KCN}$ as described in Figure 1. (A) After $168 \mathrm{~min}$, cells in the field excluded propidium (upper panel) and calcein (middle panel). No blebbing was apparent in the bright field image (lower panel). After $180 \mathrm{~min}$, calcein began to permeate the cell at the black arrow (middle panel). Calcein permeation continued and was complete after $184 \mathrm{~min}$. Bleb formation became just discernable after $183 \mathrm{~min}$ and obvious after $184 \mathrm{~min}$ (dotted arrowheads). Bleb growth continued to $189 \mathrm{~min}$. Subsequent to the onset of bleb development, propidium labeled the nucleus after $189 \mathrm{~min}$ (white arrow). (B) Brightfield images were collected from a plane of focus $3 \mu \mathrm{m}$ above that in (A). Although blebs present in (A) were not apparent after $184 \mathrm{~min}$, progressive upward bleb growth and expansion made a bleb apparent after $185 \mathrm{~min}$ (dotted arrowhead). Bleb growth continued through $189 \mathrm{~min}$ (dotted arrowheads). After bleb growth had started, propidium labeling (upper panels, same focal plane as (A) began to occur, which was barely discernable after $186 \mathrm{~min}$ and progressively more bright after 187-189 min (white arrows). One experiment representative of four

somes. ${ }^{1,6,7,10}$ The present study shows that the metastable state also occurs in hepatic sinusoidal endothelial cells during chemical hypoxia with cyanide. Previously, this permeability change was assumed to be non-specific. However, in the present study, permeation of solutes early during the metastable state showed specificity for charge and molecular weight. Organic anions like calcein with molecular weight of
$623 \mathrm{Da}$ began to permeate cells at onset of the metastable state, whereas propidium, an organic cation of $414 \mathrm{Da}$, and high molecular weight dextrans remained excluded (Figures 1, 2 and 3). Similarly, previous work in hepatocytes demonstrated leakage of anionic fluorophores like BCECF $(521 \mathrm{Da})$ and Fura-2 (636 Da) from cells during the metastable state. ${ }^{6,7}$ 

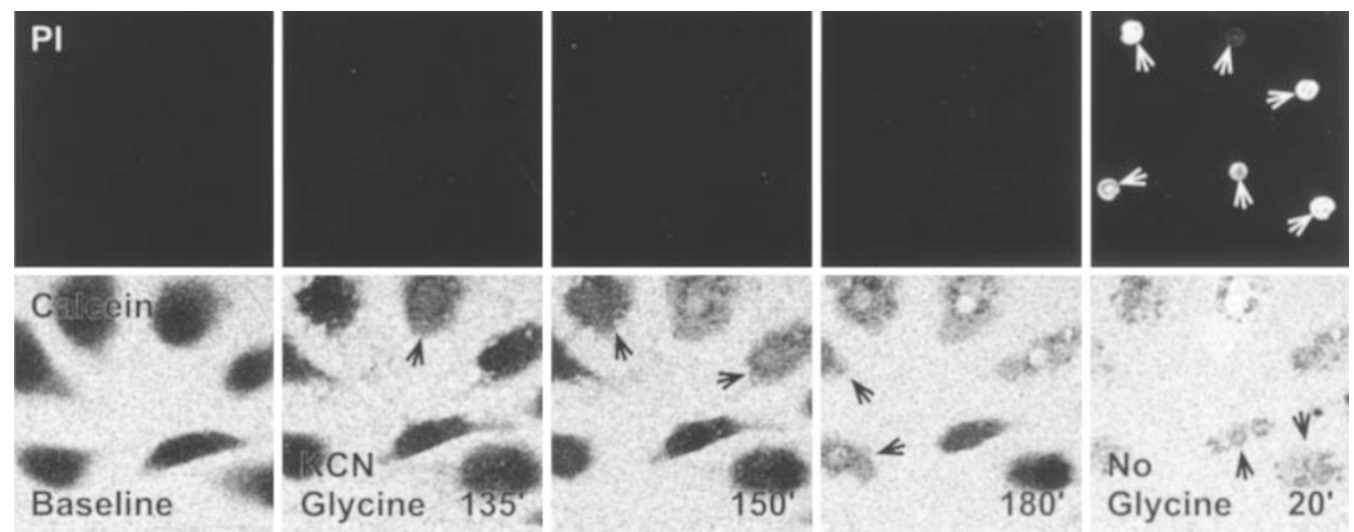

Figure 4 Effect of glycine on permeability changes in the plasma membrane during chemical hypoxia. Cells were incubated in $\mathrm{KRH}$ with $3 \mathrm{mM}$ glycine, $30 \mu \mathrm{M}$ calcein, and $3 \mu \mathrm{M}$ propidium iodide. After collection of baseline images, $2.5 \mathrm{mM} \mathrm{KCN}$ was added. Cells began to fill with calcein after $135-150$ min of chemical hypoxia (black arrows). Thirty to 45 min later, intracellular calcein had not completely equilibrated (180', lower panel). Subsequently, when glycine was removed, all nuclei labeled with propidium (No Glycine, white arrows), and cells that had not previously taken up calcein did so (black arrows). One experiment representative of four
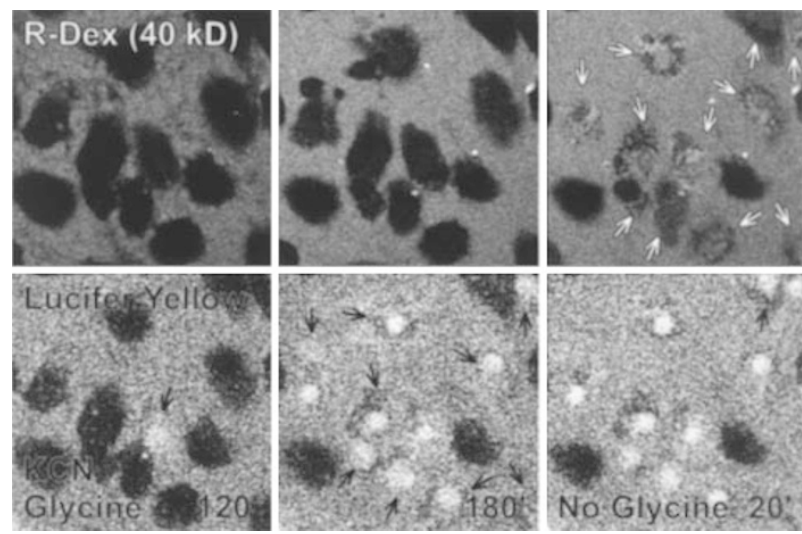

Figure 5 Permeation of the plasma membrane by lucifer yellow and rhodamine-dextran during chemical hypoxia with glycine. Cells were incubated with $2.5 \mathrm{mM} \mathrm{KCN}$ containing $30 \mu \mathrm{M}$ lucifer yellow and $40 \mathrm{kD}$ rhodamine-dextran $(0.3 \mathrm{mg} / \mathrm{ml})$. In the presence of glycine, lucifer yellow gradually penetrated the cells. After $120 \mathrm{~min}$ of chemical hypoxia with glycine one cell was fully permeated by lucifer yellow $\left(120^{\prime}\right.$, black arrow), but none of the cells were permeated with rhodamine-dextran. After $180 \mathrm{~min}$, lucifer yellow penetrated most cells (180', black arrows), but all cells still excluded rhodamine-dextran. After removal of glycine, rhodamine-dextran rapidly entered cells that had taken up lucifer yellow (No Glycine, white arrows). One experiment representative of five removing glycine in the presence of fluorescent dextran

The difference of a few minutes between permeation of calcein and propidium might represent the time necessary for propidium to bind sufficiently to yield detectable nuclear fluorescence. However, in the presence of glycine, permeation of propidium was completely blocked whereas calcein and lucifer yellow permeated virtually completely, although at a much slower rate (Figures 4 and 5). Similarly, glycine completely blocked penetration of 40 to $2000 \mathrm{kDa}$ dextrans for at least 60 minutes after the beginning of calcein entry (Figure 6). Removal of glycine quickly reversed this blockade, and both propidium and dextran rapidly entered the cells. These findings strongly suggest that propidium and dextran penetrate the plasma membrane via a different pathway than calcein.

\section{Death channel opening at onset of the metastable state}

Since the molecular weights of anionic calcein and cationic propidium are similar, differences in electrical charge may account for the difference of permeability of the fluorophores. This hypothesis is supported by the observation that lucifer yellow, another anionic fluorophore of similar molecular weight to calcein, penetrated the plasma membrane in a fashion virtually identical to calcein (Figure 5). Thus, onset of the metastable state seems initiated by opening of a channel in the plasma membrane with selective permeability to anions up to a molecular weight of at least $620 \mathrm{Da}$, such as calcein and lucifer yellow, as shown in the present study, and Fura-2 and BCECF, as shown previously. ${ }^{6,7}$ This anion channel acted as a death channel, since its opening precipitated a rapid progression of cell swelling, bleb formation, and nonspecific breakdown of the plasma membrane permeability barrier, which culminated in loss of cell viability (Figures 3 and $6)$. Glycine appeared to block conductance of this death channel (Figures 4, 5 and 6).

Previously, glycine was proposed to protect against cell killing by blocking chloride ion $\left(\mathrm{Cl}^{-}\right)$influx in the late phase of cell injury. ${ }^{25}$ Glycine was hypothesized to bind to a specific receptor regulating a chloride channel, analogous to the glycine receptor of the central nervous system. In support of this hypothesis, strychnine, another ligand of the CNS glycine receptor also protects against cell killing, ${ }^{18,19}$ see also ${ }^{16}$. Thus, chloride channel blockade is proposed to mediate cytoprotection by glycine and strychnine. ${ }^{25}$ Involvement of a $\mathrm{Cl}^{-}$-specific anion channel in glycine cytoprotection implies that $\mathrm{Cl}^{-}$-free medium should be equally cytoprotective. Although cytoprotection has been reported in low $\mathrm{Cl}^{-}$medium, ${ }^{25-27}$ other studies report no cytoprotection by $\mathrm{Cl}^{-}$-free medium. ${ }^{16,19,21}$ Specifically, $\mathrm{Cl}^{-}$free buffer does not protect hepatic sinusoidal endothelial 

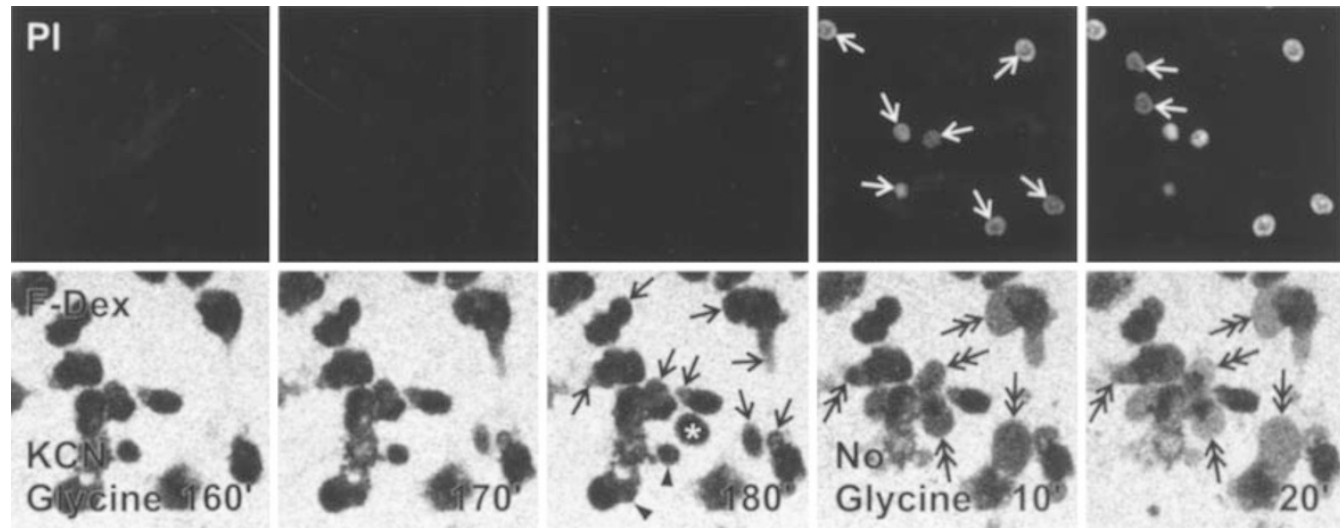

Figure 6 Effect of glycine on bleb formation. Cells were incubated with $\mathrm{KRH}$ containing $2.5 \mathrm{mM} \mathrm{KCN}, 3 \mathrm{mM}$ glycine, $3 \mu \mathrm{M}$ propidium iodide, and $2000 \mathrm{kDa}$ fluorescein-dextran $(0.3 \mathrm{mg} / \mathrm{ml})$. In the presence of glycine, no propidium uptake occurred during chemical hypoxia (160'-180', upper panels). Small blebs developed, as outlined by fluorescein-dextran (180', black arrows). When glycine was removed, many blebs rapidly increased in size (No Glycine, $10^{\prime}$ and $20^{\prime}$, double arrows), and most nuclei labeled with propidium within 10 to 20 min (white arrows). Bleb growth did not continue after propidium labeling (No Glycine, 20', double arrows). In the lower panel of $180^{\prime}$, black arrowheads indicate cells that washed away when the incubation buffer was changed. The asterisk indicates a floating cell. Note that $2000 \mathrm{kDa}$ fluorescein-dextran was partially excluded from cells even after propidium labeling, because of the molecular sieve effect of intracellular structures. During chemical hypoxia in the absence of glycine, $2000 \mathrm{kDa}$ fluorescein-dextran also was taken up in parallel with propidium labeling (not shown). One experiment representative of four

cells against reperfusion injury under conditions where glycine prevents cell killing virtually completely. ${ }^{16}$ Thus, opening of a less specific anion channel may mediate cell killing by conducting complex organic anions in addition to smaller inorganic anions. Indeed, the glycine-sensitive phase of rapid swelling and bleb formation during the metastable state implies that $\mathrm{Cl}^{-}$is entering cells rapidly. Electrophysiological techniques such as whole cell patch clamping will be required to characterize completely the conductance properties of the glycine-sensitive channel and to determine, for example, whether the channel conducts small cations like $\mathrm{Na}^{+}$and $\mathrm{K}^{+}$. Nonetheless, confocal microscopy shows directly for the first time that a glycine-sensitive channel with relative specificity for anions initiates the metastable state of cell injury that rapidly culminates in cell death.

Previously, formation of glycine-sensitive aqueous pores at onset of cell death were described in dying ATP-depleted MDCK cells. ${ }^{22}$ Unlike the anion channels described in the present work, these aqueous pores have an apparent diameter of 5-6 nm and conduct organic cations, like propidium, as well as dextrans of molecular weights up to $70000 \mathrm{Da}$. Evidence was also presented that the diameters of the aqueous pores in ATP-depleted MDCK cells increase in size over time. Thus, the pore described in MDCK cells has very different characteristics to the anion death channel described here in sinusoidal endothelial cells, except that glycine inhibits opening of both the aqueous pore and the anion channel. One hypothesis is that glycine-sensitive anion channel opening causes rapid cell swelling and stretching of the plasma membrane bilayer that lead secondarily to porous defects in the plasma membrane. Such porous defects seem to progress to outright membrane rupture in some cell types ${ }^{7,10,28}$ and allow small organic cations, like propidium, and higher molecular weight solutes, like dextran and lactate dehydrogenase, to permeate the plasma membrane. Future studies are needed to better characterize both the aqueous pore and the anion death channel and to determine what interrelationships exist between them.

\section{Mechanism of cell swelling during the metastable state}

$\mathrm{Na}^{+}$and $\mathrm{K}^{+}$gradients collapse quickly during ATP depletion due, in part, to inhibition of the $\mathrm{Na}$, K-ATPase. ${ }^{29,30} \mathrm{~K}^{+}$and $\mathrm{Na}^{+}$ channels also open during hypoxic stress. ${ }^{27,30-33}$ In the absence of entry of a counter anion, cation channel opening does not lead to large volume changes. However, if an anion channel subsequently opens, rapid colloid osmotic swelling will follow. Colloid osmotic (or oncotic) pressure is the osmotic force exerted by high molecular weight solutes. When the plasma membrane becomes permeable to electrolytes $\left(\mathrm{Na}^{+}\right.$, $\mathrm{K}^{+}, \mathrm{Cl}^{-}$) and other low molecular weight solutes, these solutes no longer exert osmotic force across the membrane. Rather, only impermeant high molecular weight solutes exert an osmotic force. These high molecular weight solutes are primarily proteins inside the cells. When colloid osmotic pressure is greater inside cells than outside, water will move into cells. Cellular swelling will continue until the plasma membrane ruptures, at which point intracellular proteins escape and the colloid osmotic pressure gradient disappears. Colloid osmotic swelling can only occur if the plasma membrane is permeable to both $\mathrm{Na}^{+}$and $\mathrm{Cl}^{+}$, since water entry without $\mathrm{NaCl}$ entry would create an osmotic pressure gradient opposing swelling.

In our experiments, swelling was evident from the rapid enlargement of plasma membrane blebs as the cells entered the metastable state (Figure 3). Glycine, which slowed anion entry, also decreased the rate of bleb formation and cell swelling. The effect of glycine in retarding bleb formation and swelling was also shown by the observation that removal of glycine from hypoxic cells produced rapid swelling and bleb growth (Figure 6). As 
rapid bleb growth continued, propidium began to enter the cells. However, bleb growth and cell swelling stopped soon after propidium labeling occurred.

At a concentration of $3 \mathrm{mM}$, glycine slowed calcein entry by $90 \%$ or more but did not completely prevent calcein permeation (Figure 4). The lack of complete conductance blockade is consistent with the fact that glycine is a relatively low affinity blocker of cell death in sinusoidal endothelial cells $\left(\mathrm{IC}_{50} \approx 0.3 \mathrm{mM},{ }^{17}\right)$. By contrast, glycine completely blocked propidium and dextran entry for prolonged periods of time (Figures 4, 5 and 6). This finding indicates that propidium and dextran entry occurs by a mechanism downstream of glycine-sensitive anion channel opening. A downstream effect is also consistent with our observation that propidium and dextran permeation in the absence of glycine follows temporally calcein entry by several minutes.

\section{Working hypothesis}

Our working hypothesis for the progression of plasma membrane permeability changes during chemical hypoxia is summarized in Figure 7. Relatively early during chemical hypoxia, ATP depletion inhibits the $\mathrm{Na}, \mathrm{K}-\mathrm{ATP}$ ase, cation channels open, and $\mathrm{K}^{+}$and $\mathrm{Na}^{+}$gradients across the plasma membrane collapse. ${ }^{27}$ Nonetheless, relatively little cell swelling occurs because the plasma membrane remains impermeable to anions. Subsequently, the glycine-sensitive anion death channel opens. This death channel is presumably identical to the glycine-sensitive chloride channel postulated earlier based on pharmacological data. ${ }^{18,25}$ Death channel

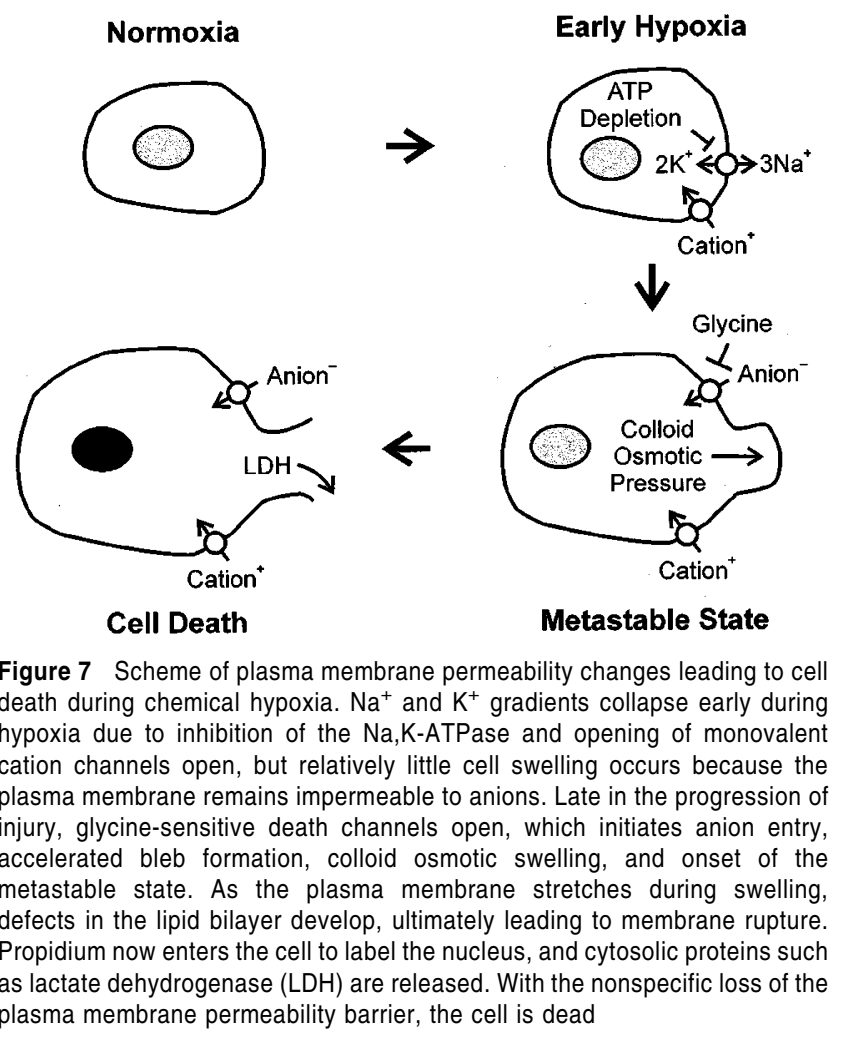

opening initiates entry of anions, swelling, bleb formation, and onset of the metastable state. Already permeant cations, mostly $\mathrm{Na}^{+}$, also enter in charge compensation for anion entry. Notably, glycine does not prevent or delay the time of opening of the postulated death channel. Rather, glycine appears to block the conductance through newly formed or opened channels. Interestingly, a cell volume regulatory anion channel also opens in apoptotic cell death. But in the presence of intact $\mathrm{K}^{+}$and electrical gradients across the plasma membrane, the anion channel promotes shrinkage during apoptosis rather than the swelling observed during necrotic cell death. ${ }^{34}$

Swelling in our model is driven by colloid osmotic forces across the plasma membrane. The involvement of colloid osmotic forces rather than simple osmotic strength explains previous observations that rates of cell killing during chemical hypoxia are insensitive to osmolarity of the medium. ${ }^{35}$ As the plasma membrane stretches during this phase of rapid swelling and bleb growth, defects in the lipid bilayer likely develop, as described previously. ${ }^{22}$ Consequently, propidium and high molecular weight dextrans begin to enter the cells. At some point, such bi-layer discontinuities become irreversible, or as we showed previously in hepatocytes and cardiac myocytes, ${ }^{7,10,28}$ the plasma membrane simply bursts. As a consequence, the plasma membrane becomes fully permeable to both low and high molecular weight solutes. After membrane breakdown, colloid osmotic pressure is no longer exerted across the plasma membrane, and swelling ceases. By inhibiting anion entry, glycine slows cell swelling and decreases the stretching of the plasma membrane to below the threshold for formation of porous defects and/or membrane rupture. The basis for opening of the glycinesensitive death channel remains unknown. In hepatocytes, onset of the mitochondrial permeability transition and breakdown of lysosomes precede onset of the metastable state. ${ }^{10}$ Thus, a hydrolytic enzyme or factor released by mitochondria or lysosomes may be important for death channel opening. The scheme in Figure 7 represents a working model to guide future investigations. Other models, such as glycine-sensitive formation of aqueous pores of increasing diameter, ${ }^{22}$ might also account for our observations. However, such aqueous pores would need to be very large, since even the largest of the dextrans used in our study $(2000 \mathrm{kDa})$ promptly entered cells at onset of cell death.

\section{Materials and Methods}

\section{Materials}

Calcein, lucifer yellow, and high molecular weight rhodamine- and fluorescein-dextrans $(40-2000 \mathrm{kDa})$ were purchased from Molecular Probes (Eugene, OR, USA); collagenase A from Boehringer Mannheim (Indianapolis, IN, USA); potassium cyanide (KCN) from Fisher Scientific (Fair Lawn, NJ, USA); and RPMI 1640 medium and fetal bovine serum from Gibco BRL (Grand Islands, NY, USA). Other reagent grade chemicals were purchased from Sigma Chemical Co. (St. Louis, MO, USA). 


\section{Isolation of sinusoidal endothelial cells}

Sinusoidal endothelial cells from the livers of male Sprague-Dawley rats $(270-330 \mathrm{~g})$ were isolated and purified by collagenase perfusion and centrifugal elutriation, as described previously. ${ }^{17}$ The purified endothelial cells were cultured overnight in RPMI 1640 medium supplemented with $20 \%$ fetal bovine serum, $2 \mathrm{mM}$ glutamine, $1 \mu \mathrm{M}$ phorbol myristate acetate and antibiotics on type I rat tail collagencoated glass coverslips.

\section{Cell injury}

To simulate the ATP depletion and reductive stress of hypoxia/ ischemia, overnight cultured endothelial cells were incubated in KrebsRinger-HEPES buffer (KRH) (in $\mathrm{mM}$ : $\mathrm{NaCl} 115, \mathrm{KCl} 5, \mathrm{CaCl}_{2} 2$, $\mathrm{KH}_{2} \mathrm{PO}_{4} 1, \mathrm{MgSO}_{4}$ 1.2, HEPES 25, pH 7.4) and exposed to $2.5 \mathrm{mM}$ $\mathrm{KCN}$, an inhibitor of mitochondrial cytochrome oxidase (chemical hypoxia). Previous experiments showed that $\mathrm{KCN}$ causes rapid ATP depletion. ${ }^{17}$

\section{Confocal microscopy}

Overnight cultured cells were mounted in a temperature-controlled chamber (Bioptecs Inc., Butler, PA, USA) and placed on the microscope stage in $\mathrm{KRH}$ containing $30 \mu \mathrm{M}$ calcein, $3 \mu \mathrm{M}$ propidium iodide, $30 \mu \mathrm{M}$ lucifer yellow, $0.3 \mathrm{mg} / \mathrm{ml}$ fluorescein-dextran, and/or $0.3 \mathrm{mg} / \mathrm{ml}$ rhodamine-dextran. Fluorescence was imaged with a Zeiss LSM 410 laser scanning confocal microscope (Thornwood, NY, USA) through a $63 \times$ N.A. 1.4 oil-immersion planapochromat objective. An argon/krypton mixed gas laser provided $488 \mathrm{~nm}$ and $568 \mathrm{~nm}$ excitation light. Emitted fluorescence was divided by a $560-\mathrm{nm}$ dichroic mirror and directed to individual photomultipliers through a $515-540 \mathrm{~nm}$ band pass barrier filter (green) and a $590 \mathrm{~nm}$ long pass barrier filter (red). ${ }^{10,17,36}$ In both channels, the pinhole was set to an Airy unit of $0.9-1.1$. Gain and brightness controls were adjusted to avoid pixel over- and under-saturation. Non-confocal bright field images were simultaneously collected using a transmitted light detector.

\section{Acknowledgements}

This work was supported, in part, by Grants DK37034, AG13637 and AA11605 from the National Institutes of Health. Core imaging facilities were supported, in part, by 1-P50-AA11605 and 5-P30-DK34987 to the Center for Alcohol Studies and the Center for Gastrointestinal Biology and Disease. Portions of this work were presented at the 47th Annual Meeting of the American Association for the Study of Liver Diseases, Chicago, IL, USA, November 8-12, 1996.

\section{References}

1. Herman B, Nieminen A-L, Gores GJ and Lemasters JJ (1988) Irreversible injury in anoxic hepatocytes precipitated by an abrupt increase in plasma membrane permeability. FASEB J. 2: 146-151

2. Gores GJ, Herman B and Lemasters JJ (1990) Plasma membrane bleb formation and rupture: a common feature of hepatocellular injury. Hepatology 11:690-698

3. Chien KR, Abrams J, Serroni A, Martin JT and Farber JL (1978) Accelerated phospholipid degradation and associated membrane dysfunction in irreversible, ischemic liver cell injury. J. Biol. Chem. 253: 4809-4817

4. Farber JL and Young EE (1981) Accelerated phospholipid degradation in anoxic rat hepatocytes. Arch. Biochem. Biophys. 211: 312-320
5. Wang H, Harrison-Shostak DC, Lemasters JJ and Herman B (1996) Contribution of $\mathrm{pH}$-dependent group II phospholipase $\mathrm{A}_{2}$ to chemical hypoxic injury in rat hepatocyte. FASEB J. 10: 1318-1325

6. Gores GJ, Nieminen A-L, Wray BE, Herman B and Lemasters JJ (1989) Intracellular pH during "chemical hypoxia" in cultured rat hepatocytes. J. Clin. Invest. 83: 386-396

7. Nieminen A-L, Gores GJ, Wray BE, Tanaka Y, Herman B and Lemasters JJ (1988) Calcium dependence of bleb formation and cell death in hepatocytes. Cell Calcium 9: 237-246

8. Majno G and Joris I (1995) Apoptosis, oncosis, and necrosis. An overview of cell death. Am. J. Path. 146: 3-15

9. Hoffstein S, Gennaro DE, Fox AC, Hirsch J, Streuli F and Weissmann G (1975) Colloidal lanthanum as a marker for impaired plasma membrane permeability in ischemic dog myocardium. Am. J. Path. 79: 207-218

10. Zahrebelski G, Nieminen A-L, Al-Ghoul K, Qian T, Herman B and Lemasters JJ (1995) Progression of subcellular changes during chemical hypoxia to cultured rat hepatocytes: a laser scanning confocal microscopic study. Hepatology 21: $1361-1372$

11. Weinberg JM, Davis JA, Abarzua M and Rajan T (1987) Cytoprotective effects of glycine and glutathione against hypoxic injury to renal tubules. J. Clin. Invest. 80: 1446- 1454

12. Zagar RA, Schimpf BA and Gmur DJ (1993) Physiological pH: effect on posthypoxic proximal tubular injury. Circ. Res. 72: 837-846

13. Dickson RC, Bronk SF and Gores GJ (1992) Glycine cytoprotection during lethal hepatocellular injury from adenosine triphosphate depletion. Gastroenterology 102: $2098-2107$

14. Wetzels JF, Wang X, Gengaro PE, Nemenoff RA, Burke TJ and Schrier RW (1993) Glycine protection against hypoxic but not phospholipase $A_{2}$-induced injury in rat proximal tubules. Am. J. Physiol. 264: F94-F99

15. Bachmann S, Peng X-X, Currin RT, Thurman RG and Lemasters JJ (1995) Glycine in Carolina rinse solution reduces reperfusion injury, improves graft function, and increases graft survival after rat liver transplantation. Transplant. Proc. 27: $741-742$

16. Currin RT, Caldwell-Kenkel JC, Litchman SN, Bachmann S, Takei Y, Kawano S Thurman RG and Lemasters JJ (1996) Protection by Carolina rinse solution acidotic $\mathrm{pH}$, and glycine against lethal reperfusion injury to sinusoidal endothelial cells of rat livers stored for transplantation. Transplantation 11: 1549-1558

17. Nishimura Y, Romer LH and Lemasters JJ (1998) Mitochondrial dysfunction and cytoskeletal disruption during chemical hypoxia to cultured hepatic sinusoidal endothelial cells: the $\mathrm{pH}$ paradox and cytoprotection by glucose, acidotic $\mathrm{pH}$ and glycine. Hepatology 27: 1039-1049

18. Miller GW, LockEA and Schnellmann RG (1994) Strychnine and glycine protect renal proximal tubules from various nephrotoxicants and act in the late phase of necrotic cell injury. Toxicol. Appl. Pharmacol. 125: 192-197

19. Venkatachalam MA, Weinberg JM, Patel Y, Saikumar P and Dong Z (1996) Cytoprotection of kidney epithelial cells by compounds that target amino acid gated chloride channels. Kidney Int. 49: 449-460

20. Nichols JC, Bronk SF, Mellgren RL and Gores GJ (1994) Inhibition of nonlysosomal calcium-dependent proteolysis by glycine during anoxic injury of rat hepatocytes. Gastroenterology 106: 168-176

21. Qian T, Nieminen A-L, Herman B and Lemasters JJ (1997) Mitochondria permeability transition in $\mathrm{pH}$-dependent reperfusion injury to rat hepatocytes. Am. J. Physiol. 273: C1783-C1792

22. Dong Z, Patel Y, Saikumar P, Weinberg JM and Venkatachalam MA (1998) Development of porous defects in plasma membranes of adenosine triphosphate-depleted Madin-Darby canine kidney cells and its inhibition by glycine. Lab. Invest. 78: 657-668

23. Lemasters JJ, BunzendahlH and Thurman RG(2001) Preservation of the liver. In Transplantation of the Liver, Third Edition, Maddrey WC, Schiff ER and Sorrell MF, eds. (Philadelphia: Lippincott, Williams \& Wilkins), pp 251-273

24. Nieminen A-L, Gores GJ, Bond JM, Imberti R, Herman B and Lemasters JJ (1992) A novel cytotoxicity assay using a multi-well fluorescence scanner. Toxicol. Appl. Pharmacol. 115: 147-155

25. Miller GW and Schnellmann RG (1993) Cytoprotection by inhibition of chloride channels: the mechanism of action of glycine and strychnine. Life Sci. 53: 12031209 
26. Miller GW and Schnellmann RG (1995) Inhibitors of renal chloride transport do not block toxicant-induced chloride influx in the proximal tubule. Toxicol. Lett. 76 $179-184$

27. Carini R, Bellomo G, Grazia De Cesaris M and Albano E (1997) Glycine protects against hepatocyte killing by KCN or hypoxia by preventing intracellular $\mathrm{Na}^{+}$ overload in the rat. Hepatology 26: 107-112

28. Bond JM, Herman B and Lemasters JJ (1991) Recovery of cultured rat neonata myocytes from hypercontracture after chemical hypoxia. Res. Commun. Chem. Pathol. Pharmacol. 71: 195-208

29. Kawanishi T, Nieminen A-L, Herman B and Lemasters JJ (1991) Suppression of $\mathrm{Ca}^{2+}$ oscillations in cultured rat hepatocytes by chemical hypoxia. J. Biol. Chem. 266: $20062-20069$

30. Carini R, Autelli R, Bellomo G and Albano E (1999) Alterations of cell volume regulation in the development of hepatocyte necrosis. Exp. Cell Res. 248: 280293

31. Ju Y-K, Saint DA and Gage PW (1994) Inactivation-resistant channels underlying the persistent sodium current in rat ventricular myocytes. Proc Royal Soc London B 456: 2 -8
32. Noma A (1983) ATP-regulated $\mathrm{K}^{+}$channel in cardiac muscle. Nature 305: 147 148

33. Haddad GG and Jiang C (1994) Mechanisms of neuronal survival during hypoxia: ATP-sensitive $\mathrm{K}^{+}$channel. Biol. Neonate 65: 160-165

34. Lang F, Uhlemann AC, Lepple-Wienhues A, Szabo I, Siemen D, Nilius B and Gulbins E (1999) Cell Volume Regulatory Mechanisms in Apoptotic Cell Death. Herz 24: 232-235

35. Gores GJ, Flarsheim CE, Dawson TL, Nieminen A-L, Herman B and Lemasters JJ (1989) Swelling, reductive stress and cell death during chemical hypoxia in hepatocytes. Am. J. Physiol. 257: C347-C354

36. Nieminen A-L, Saylor AK, Tesfai SA, Herman B and Lemasters JJ (1995) Contribution of the mitochondrial permeability transition to lethal injury after exposure of hepatocytes to t-butylhydroperoxide. Biochem. J. 307: 99-106 